\title{
On Some Topical Issues of the Chinese Nuclear Energy Terminology
}

\author{
Aryuna Ivanova ${ }^{1}$, Antonina Berdyklycheva ${ }^{2} \&$ Nadezhda Saltanova ${ }^{3}$ \\ ${ }^{1}$ Economic Faculty, Department of Foreign Languages RUDN University, Moscow, Russia \\ ${ }^{2}$ RE Inkor Ltd, Moscow, Russia \\ ${ }^{3}$ Chinese Language Department, Institute of Foreign Languages, Moscow City University, Moscow, Russia \\ Correspondence: Aryuna Ivanova, Economic Faculty, Department of Foreign Languages, RUDN University, \\ Miklukho-Maklaya str. 6, Moscow, Russia. E-mail: ivanova-ag@rudn.ru, ariunadi@mail.ru
}

$\begin{aligned} & \text { Received: July 18, } 2020 \\ & \text { Accepted: August 28, } 2020 \quad \text { Online Published: September 27, } 2020 \\ & \text { doi:10.5539/ijel.v10n6p298 }\end{aligned} \quad$ URL: https://doi.org/10.5539/ijel.v10n6p298

\begin{abstract}
The article touches upon the issues of the nuclear energy terminology. It considers definitions of a term and the development of terminology, as a field of science. Taking Chinese nuclear energy terms as an example, the article traces the origin and contemporary challenges of the Chinese terminology as a branch of the Chinese linguistics. ISO/IEC standards in the field of nuclear energy are defined as the basis for processing first English nuclear energy terms and further for Chinese terms development. Analysis of the examples of terms and their translations confirm the importance of taking into account the criteria of standardization. The necessity of ISO/IEC standards is seen as a key factor in conducting linguistic translation analysis of terms and for creating Chinese corpus of terms and definitions for nuclear energy. Therefore, the terms' translation is not only the work of the translation community, but also work which all relevant state departments should accomplish together and in cooperation.
\end{abstract}

Keywords: ISO/IEC standard, nuclear power, nuclear energy, term, terminology

\section{Introduction}

\subsection{Problem Statement}

The article attempts to dwell upon the achievements and topical issues of translation and standardization of nuclear energy terms. The relevance of this research lies in the mass need for terminology standardization discussion in this field. Nuclear power is currently one of the most "international" fields of human activity. This is related to both tightening of international requirements for the safety of nuclear power plants after accidents and the intention of an increasing number of countries, which develop national nuclear energy programs. In China, India, the Republic of Korea, the USA, Canada and Finland, programs for the intensive development of nuclear energy are being formulated and implemented. Some countries that have not established nuclear power plants yet, including Turkey, Belarus, Poland, Vietnam, Indonesia, Morocco and others, have declared their intentions to develop the nuclear power industry. Therefore, the terminology of this fast-growing industry as well as the development of the nuclear power industry and related fields require scientific reflection (Zhao, 2004; Yuan et al., 2014; Zhang et al., 2015; Yuan et al., 2016; Wang et al., 2016; Wu et al., 2017; Xu et al., 2017; Zhao et al., 2017).

The study of terminology standardization and the practice of creating these standardizations for public use were made in large part by the works of academics such as Toury (1980), Crystal (2010), Milroy (2001) and others. It is imperative to define terminological fields, microfields and nests of the nuclear power system terminology, to identify sources and methods of forming nuclear power terminology and systematize nuclear power terminology in accordance with both the areas of their operation and basing on the term formation mechanisms. Some research papers on standardization of terms in Chinese are performed by Quan (2005), Liu (2008), Huang (2010) etc.

The need to study the formation of nuclear energy terminology, its systematization and standardization, and development trends arises from the specific communication objectives of the area itself. Since communication is a core pillar of human existence, it is important and justified to comprehend communication between people, to understand what is hindering and what contributes to it. Therefore, to maintain this pillar within the industry, it is 
required to single out a corpus of nuclear energy terminology based on a study of existing industry thematic dictionaries and glossaries and fulfill a research on nuclear energy terms.

The main hypothesis that runs along this study is that the terminology system of the Chinese nuclear energy is formed; most of the terms come from the related fields of knowledge. Still further research on the terminology system of nuclear power is required for its further systematization, unification and standardization.

The theoretical significance of this study comes from the fact that the data obtained from the description of the terminological system of nuclear energy can be extrapolated to the terminology systems of other subject areas, which contributes to the improvement of methods for analyzing industry terminology.

The practical significance of the work lies in the possibility of using materials, key points and conclusions in the development of special courses, seminars and workshops on language training for the assistance of specialists in the field of nuclear energy, as well as in their professional activities and intercultural communication. The practical value also lies in the development of a bilingual nuclear energy terminological dictionary, which can be used as a universal manual for specialists in the field of nuclear energy and technical translation.

\subsection{Importance of the Problem}

Linguistics nowadays pays more attention to linguistic analysis of special vocabulary of various fields of knowledge-terms. Researchers analyze special vocabulary, which denotes categories, concepts, elaborate research methods and techniques to process and classify special lexemes. Among such words there is a dominating majority defined as terms, which naming various phenomena form terminological systems. Moreover, each term system denotes a system of notions for an individual science or scientific directions and encounter different problems at that (Malyuga \& Orlova, 2016; Malyuga \& Tomalin, 2015).

Although terminology of natural sciences has kept pace with scientific developments, due to the essence of this field of science and the elaborated agreement on the nature and status of the concepts. For other fields of arts and science, i.e., Linguistics, it is rather an open question. As the latter deals with humans' language and the observation of which is available in the forms of its manifestations, texts mainly, and diversification of views over the same phenomenon lead to a variety of definitions or terms. Therefore, three main problems defined for linguistic terminology, namely the categories underlying the terminology, the terms themselves, and the proliferation of terms, leading to the 'translation problem' (Walmsley, 2006; Anisimova, Malakhova, \& Abdulrahimov, 2019; Anisimova \& Pavlyuk, 2018) to some extent can be applied to any language which processes terms system in different fields of science.

In the frame of the present research based on the applied approach, we attempt to answer the following questions: What principles must be regarded as main for establishing and further development of Chinese nuclear power terminology? What international standards in elaborating nuclear energy terms for Chinese should be considered and why? What are the peculiarities of translation of nuclear energy terms from English to Chinese?

The objective of the current research is to conduct a comparative analysis of the two languages' terminologies on the account of the terminological base, which is now in force within international organizations for standardization. In accordance with this objective, the following tasks have been set:

- Analyze current methods and shortcomings of translation practices;

- Identify the standardization process of terminology;

- Recognize outside factors affecting said standardization and translation;

- Mark existing developments in the field.

\subsection{Relevant Scholarship}

Terminology as a branch of Linguistics started in 1930. At present, there are several national schools of terminology-Austrian-German, French-Canadian, Russian and Czech - that differ by their approaches and main aspects of research.

Nowadays, there is a variety of conceptual approaches to the interpretation of the concept "term", which determines the diversity of its definitions in Linguistics. The approaches to the study of "term" can be summed up as follows:

1) According to a substantial approach, terms are special words or phrases unlike other nominative units are characterized by monosemanticism, accuracy, consistency, contextual independence and emotional neutrality (Lotte, 1961; Aleksandrovskaya, 1973; Golovin, 1981, 1987 and others). As many terms hardly meet these strict requirements, this approach to the interpretation of the concept of "term" has 
always been criticized.

2) Functional approach states that any word can be a term, as words may have a special function (Vinokur, 1939; Leichik, 1971; Moiseev, 1971 and others). Though terms are characterised by a number of functions (nominative, significative, communicative, pragmatic or expressive, heuristic), those functions to some extent are presented in words with general meanings.

3) Linguistic approach, on the contrary, defines a term as a word or a word-combination of a special (scientific, technical etc.) language (Akhmanova, 1966; Leichik, 2006; Superanskaya, 2009 and others). Leichik states that, "term" is an object of a number of sciences and each science seeks to highlight the signs significant for this particular science (Leichik, 2006). Great number definitions of a "term" in linguistics is explained by Superanskaya by the fact that in different disciplines the concept is associated with specific notions (Superanskaya, 2009). Grinev defines the term as "nominative special lexical unit (word or phrase) of a special language, adopted for the exact naming of special concepts (Grinev, 1993).

Discussions over the issue are still controversial and both the interpretation of the concept "term" and the formulating its definition remains a topical task of terminology.

In China, the definition of the terminology (in Chinese “术语学 shùyǔxué') as an independent linguistic field with its own range of tasks dates back to the late 1990s. However, even in antiquity, Chinese science and technology reached unprecedented heights. The need for the right item names, whether material subject or abstract philosophical concept, confronted the ancient Chinese with a choice in applying the correct name. Therefore, we can talk about ancient terminological traditions of the Chinese civilization. The origins of the Chinese term creation we can find in works of ancient Chinese philosophers. In the treasury of Chinese philosophical thought, in the works of Confucius 孔子 “荷子”, Xúnžr, and other philosophers we can meet brilliant ideas and thoughts on terminology.

According to Qiu (2018), there are several main institutions and termbases at national level, they are the National Standardization Technical Committee (NSTC), the China National Institute of Standardization (CNIS) and China National Committee for Terms in Sciences and Technologies (CNCTST); the terminological database in China National Committee for Terms in Sciences and Technologies, Mechanical engineering terminological database, the Chinese Encyclopedia terminological database, the Chinese-English and English-Chinese technological and scientific terminological Database, the Terminological Database for the applied Linguistics. Professor Feng Zhi Wei and Professor Zheng Shu Pu should be mentioned as great scholars and pioneers in the development of modern terminology in China (ibid, 2018).

However, the categorical-conceptual apparatus has been undergoing review and development till this day. Studies are being carried out both by foreign and Chinese scholars. The range of issues is quite various: the most topical issues of Chinese terminology, on the one hand (Ivanov, 1993; Kaarpova et al., 2007), and the theory and practice of foreign terminology, on the other (Ye Qi Song, 2010; Zheng Shu Pu et al., 2010). There are two areas of scientific research carried by the China National Committee for Terms in Sciences and Technologies theoretical research and practical work to streamline and standardize terms. A significant result of practical work was the release of 58 collections of standardized terms (Ochirov et al., 2015).

The issues of the Chinese terminology in the field of nuclear energy basing on the structure of English terminology involves standardization in the translation process. The definition of "standardization" by Toury (1980) runs that standardization is a category of descriptive analysis of translation, the values and concepts shared in a certain translation society. These include what is correct, what is wrong, what is appropriate, and what is inappropriate in any given specific situation. Toury defines standardization from the perspective of translation studies, emphasizing the position of norms in translation behavior, and regards correctness and appropriateness as the standards that translation should follow.

Liu (2004) defines standardization of terminology as a language form provided by the language system at a relatively stable state. The form, which is correctly expressed and accepted by most people. He explores standardization from the perspective of traditional linguistics, emphasizing the stability of the state of the language system, and the correctness and acceptability of the linguistic form. According to the author, in standardization process it is important to remember that it cannot be necessarily regulated. Different languages clearly do not have exactly the same language form. Therefore, it is impossible to have absolutely the same standards. In addition to standards, language habits and conventions also play a crucial role in elaborating language norms. Finally, the research purpose of the correctness and standardization of language is to ensure the relative stability of standard language application. The purpose of the standardization of terminology is to 
translate foreign language terminology accurately in order to facilitate the reference and use of terminology and concepts.

An international cooperation in any special field requires the usage of professional language whose terminological unity is meant to enhance communication processes. In the field of nuclear power, such language of international communication is traditionally English. Therefore, terminology study is needed to single out a corpus of nuclear energy terminology based on a study of existing industry thematic dictionaries and glossaries.

\section{Method}

\subsection{Sampling Procedures}

For the purpose of the study, which is carried out within the realm of Linguistics, it is necessary to mention that principles and methods for standardization of Chinese terminology are based on the ISO/704 "Terminology work. Principles and Methods". The most well-known source of terminology information is the IAEA Safety glossary developed by the International Nuclear Energy Agency. The China National Institute of Standardization (CNIS) is in charge of elaborating national standards for Chinese terms for ISO/TC 37 "Language and Terminology" Committee. The IAEA glossary is considered to contain the interpretations of nuclear energy terms approved and recognized by the international community.

However, it is significant to consider the origins of this study basis, as it provides context for the research in general. Let us first trace the modern state of the field of English nuclear energy terminology. The basis for English terminology in the field of electronics and electrical engineering, which comprises one of the important constituents of nuclear energy production and use, was established within the frames of International Electrotechnical Commission (hereinafter IEC) in 1906, far before nuclear energy production became possible in practice. In 1947, the International Organization for Standardization (hereinafter ISO) started its activity. Later in 1956, Technical Committee ISO/TC 85 "Nuclear energy, nuclear technologies, and radiological protection" (hereinafter ISO/TC 85) was created.

ISO and IEC work in mutual cooperation according to ISO \& IEC Directives on technical work. The structure of both organizations comprises a complex of Technical Committees (hereinafter TC), each of the TCs starts its activity with creation of terms and definitions standard. Up to now there are six ISO terminology standards in the areas of nuclear energy, nuclear technologies, and radiological protection (four of them are published, and two of them are under development) and "Electropedia: The World's Online Electrotechnical Vocabulary", which is a terminology dictionary, established and continuously improved by IEC. "Electropedia" is freely available.

Both ISO and IEC cooperate actively with international organizations in the field of nuclear energy, which also take part in creating terms and definitions for ISO/IEC terminology standards. Over time, this activity resulted in the formation of an internationally recognized English terminological corpus, which is continuously updated and improved, but terms formation mechanisms are not yet sufficiently investigated from the linguistic point of view. ISO vocabularies, as it is stated by ISO, are "intended to facilitate communication and promote common understanding".

China is an active member of both ISO (including ISO/TC 85) and IEC, and Chinese specialists take part in the development of English terminology bases, which gives them an option for implementing these achievements into Chinese practice. This means creating adequate translation into Chinese and creating a Chinese corpus of terms and definitions for nuclear power energy.

As for Chinese terminology in the field of nuclear energy, its development began a few decades later than that of English, and it is based upon the structure of English terminology. Nowadays, Chinese standards comprise often the direct implementation of ISO/IEC standards, and include terminological clauses. Therefore, Chinese standards (as well as International ones) can be considered as one of the main sources of information for linguistic research in nuclear energy field. Therefore, using ISO/IEC standards as the material for the study seems to be justified.

\subsection{Research Material}

As research material, the following IAEA texts in English have been chosen:

1) IAEA-TECDOC-1516 "Viability of inert matrix fuel in reducing plutonium amounts in reactors"

2) IAEA-TECDOC-1529 "Management of reprocessed uranium"

3) IAEA-TECDOC-1707 "Regulatory oversight of safety culture in nuclear installations"

4) IAEA-TECDOC-1804 "Attributes of full scope level 1 Probabilistic Safety Assessment (PSA) for applications 
in nuclear power plants"

5) IAEA-TECDOC-1806 "Nuclear power plant outage optimization strategy"

The following texts in Chinese have been chosen:

1) 中国煤炭资源可持续利用的经济学研究 (Economic Research on Sustainable Utilization of Coal Resources in China) (2015).

2) 低碳约束下中国核电发展及其规模分析(Development and scale analysis of China's nuclear power under low carbon suppression conditions) (2015).

3) 中国能源消费的二氧化碳排放时空特征分析 (Analysis of temporal and spatial characteristics of carbon dioxide emissions from China's energy consumption industries) (2015).

4) A multi-language "English-Chinese, Chinese-English Nuclear Security Glossary" (2008) was also used.

\section{Results and Discussion}

In this work we follow the definition given by Leichik, according to which a term is a word or phrase of a special (scientific, technical, etc.) language, created (adopted, borrowed, etc.) for the exact expression of special concepts and designation of special subjects (Leichik, 2006, p. 116).

Some properties of a term, such as consistency, accuracy, unambiguity and stylistic neutrality, can manifest themselves only within the framework of the term system.

The system of terms is an adequate reflection of the system of analyzed concepts, since the system of concepts is a logical model of a special area of knowledge or activity, and the terminological system is a linguistic model of this area (ibid, 116). While translating special scientific-technical vocabulary, it is necessary to use linguistic and cultural approaches, as term is a word (or phrase) of a special domain or subject field, a name of a special concept, which requires a definition. According to Barkhudarov (1975), in the theory of term translation, the following methods are used:

- calques or literal translation,

- translation transliteration and transformation,

- finding terminological equivalent,

- descriptive translation method.

The main principle in term's translation is the principle of reliability that helps to achieve the correctness and faithfulness of a translated term in a target language (TL) to a term in a source language (SL) (Kochergin, 2017).

For the purposes of the research, some terms and their definitions have been compared. Most of them are translated with the help of literal translation or calques, for the names of the terms, and descriptive method, for translation of the terms' definitions.

- The term "fissionable material" in general, is an isotope or a mixture of isotopes capable of nuclear fission. Some fissionable materials are capable of fission only by sufficiently fast neutrons (e.g., neutrons of a kinetic energy above $1 \mathrm{MeV}$ ). “可裂变材料”, 一般而言, 指能产生核裂变的一种 同位 素或同位素混合物。有些可裂变材料只有在足够快的中子(如动能超过 $1 \mathrm{MeV}$ 的中子)作用下才能 发生裂变。

- The term "hydrodynamic experiment" is an experiment used to simulate the implosion process of a nuclear explosive. It uses other materials such as U-238, tungsten and steel as substitute for fissile materials such as HEU or Pu-239 in a nuclear device, and uses the high explosive to compress the whole or partial structure of the device. “流体动力学实验”为模拟核爆炸内爆过程所进行的实验。它 是用代用材料(如铀-238、铇、钢等)替代核装置中的裂变材料高浓铀或钚-239、用高能炸药爆炸 压 缩该装置的整体或部分结构而进行的一种实验。

- The term "indirect use material" is referred to all nuclear material except direct use material. It includes: depleted, natural and low enriched uranium, and thorium, all of which must be further processed in order to produce direct use material”. “非直接使用材料”, 除直接使用材料以外的所有核材料。它包 括: 贫化铀、天然铀和低浓缩铀以及钍, 所有这些材料都必须经过进一步加工以生产直接使用 材 料。

- The term "induced-radioactivity bomb" is a type of hydrogen bomb that utilizes radioisotopes induced by neutrons during a nuclear explosion to increase radioactive contamination. In February 1950 Hungarian physicist Leo Szilard published the concept of this bomb - the "cobalt bomb". However, no 
state manufactures and tests this kind of bomb. “感生放射性弹” 利用核爆中子感生的放射性同位素 增大放射性沾染的一种氢弹。1 950 年 2 月匈牙利物理学 L 西拉德最早提出这种弹的设想一“钴 弹”。但并没有人制造和试验。

- The term "isotope separation factor" is used as a characteristic value for measuring separative efficiency of a separative unit. It is the ratio of the relative concentration after and before processing. “同位素分离 因子”表征分离单元分离效果的特征量，表示某一分离效应所产生同位素相对丰度的变化情况。

- The term "lifespan of nuclear weapon" describes the whole period of a nuclear weapon's life, beginning from when it was produced until when it could no longer fulfill technical performance criteria or meet operational requirements “核武器寿命” 核武器从出厂到无法满足技术性能指标和作战使用要求的 整个过程的期限。

As any special domain, the sphere of nuclear energy contains abbreviated terms. Abbreviations are units that represent the result of an abbreviation process - a method of word formation that combines all types of complex-contracted and abbreviated names. They are translated with the help of calques.

NT - heat treatment (热处理).

BWR - Boiling Water Reactor (沸水堆).

HEU - High-Enriched Uranium (高浓铀).

LEU - Low-Enriched Uranium (低浓铀).

NEM - Nuclear-Explosive Material (核爆材料).

MNSR - Miniature Neutron Source Reactor (微型中子源反应堆).

In the language of nuclear energy, there can be distinguished terminonyms - special names that include proper nouns and perform terminological functions. They are mostly transliterated, for example:

- Carnot cycle - 卡诺循环,

- Bohr model - 玻尔模型.

In translating sentences:

1) Already the world's largest consumer of energy, the USA, which built its industrial might on the back of enormously rich resources of fossil fuels, is importing nearly two - thirds of the oil that it consumes.

美国作为世界最大能源消耗国，在丰富化石燃料资源的支撑下建立了强大的工业实力，其消耗 的将近三分之二石油仍然通过进口取得。

2) The moderator also acts as the coolant, but becomes radioactive during operation and is circulated through a heat exchanger linked to an external, non-radioactive supply of water that turns to steam and drives the turbines.

减速剂也起到冷却作用, 但是在运行过程中呈放射性。减速剂在运行过程中穿过热能转换器, 这个热能转换器接触到外部不带放射性水, 这些水将会变成蒸汽驱动涡轮机发电。

The original expression order (1) is consistent with the Chinese expression habits. Therefore, the translation does not make many changes to the original sentence order. In the original text (2), however, the attributive clause is too long to use the forward or reverse translation method. Therefore, the translation is reorganized according to the Chinese logic and word-order to form the final translation.

Some terns in Chinese have broader meaning. The term "clearance" is used in two or more distinct safety related contexts: to mean an administrative mechanism for removing regulatory control from material and for a biological process affecting the movement of inhaled radionuclides in the body.

\section{指解除材料监管控制的管理机制，也可用来指影响体内吸入放射性核素迁移的生物过程。}

1) Removal of regulatory control by the regulatory body from radioactive material or radioactive objects within notified or authorized facilities and activities.

Removal from regulatory control in this context refers to regulatory control applied for radiation protection purposes.

Conceptually, clearance-freeing certain materials or objects in authorized facilities and activities from further control-is closely linked to, but distinct from and not to be confused with, exemption - determining that controls do not need to be applied to certain sources and facilities and activities. 
Various terms (e.g. 'free release') are used in different states to describe this concept.

2) The net effect of the biological processes by which radionuclides are removed from a tissue, organ or area of the body.

However, in Chinese, the term can be used to refer to the management mechanism for the release of material regulatory control, and can also be used to refer to impact. It can also be translated as "biological process of inhaling radionuclide migration".

\section{指解除材料监管控制的管理机制，也可用来指影响体内吸入放射性核素迁移的生物过程.}

According to the definition in IAEA Safety Glossary, the term "radioactive" means:

1) Exhibiting radioactivity; emitting or relating to the emission of ionizing radiation or particles (adjective). This is the 'scientific' definition, and should not be confused with the 'regulatory' definition.

2) Designated in national law or by a regulatory body as being subject to regulatory control because of its radioactivity (adjective). This is the 'regulatory' definition, and should not be confused with the 'scientific' definition.

However, in Chinese, it is commonly understood scientifically: if something exhibits a radiation phenomenon, or according to a less accurate but generally accepted usage, if it contains any substance that exhibits radioactivity, then the thing is described as radioactive. This provides a bit of a broader definition than what was previously stated.

在科学上, 如果某种东西表现出放射现象, 或者按照一种不那么准确但被普遍接受的用法, 如果它含有 任何表现出放射性的物质, 那么这种东西就被描述为放射性的。因此, 在科学上, 实际上任何物质（包 括被认为是废物的物质) 都是放射性的。然而, 普遍的监管做法是对放射性物质和放射性废物等术语的 定义仅包含那些由于其具有的放危害而受到监管的物质或废物。尽管准确的技术标准在国与国之间有所 不同但这种定义典型地排除了含有极低放射性核素的物质和废物以及那些仅含天然”浓度的天然放射性 核素的物质。

As for the term "nuclear power", it should be mentioned that there are two words in Chinese: 核电 and 核能. However, while translating from Chinese it should be more preferable to use "nuclear energy", because the content of the original book deals with nuclear energy and not just nuclear power. The Chinese term corresponding to "nuclear reactor" is “核反应堆” and “核反应器”, the choice of translation depends on the specific meaning of the original text.

\section{Conclusion}

The study analyzed terms of nuclear energy in English and Chinese. After analyses of a "term" definitions, it can be defined as a word or phrase that exists within a particular special (professional) field of knowledge, meaning a special concept of this field that requires strict definition. It is used in special conditions and is a verbalized result of professional thinking.

The term "nuclear energy" has a scientific and technical meaning that accurately and unambiguously expresses the concept of the nuclear industry. Despite the large number of borrowings from adjacent fields of knowledge, the terminological system of the nuclear energy language can be recognized as independent since it has its own established corpus of terminological units and concepts.

According to the results of the study, in translation of the terms from English to Chinese, such methods as calques, transliteration and descriptive method are used. Nuclear terminology has a specific meaning and each term is thus irreplaceable. Therefore, it is of great importance to translate these technical terms correctly. To fulfill this task a translator should meet requirements on theoretical and professional subject knowledge. Relevant institutions of the state should propose the norms of terminology translation, publish new terminology translation immediately, supervise the translation of terminology in order to accomplish standardization and unification. Therefore, the terms' translation is not only the work of the translation community, but the work, which all relevant state departments should participate in and collaborate with.

\section{Acknowledgments}

The publication has been prepared with the support of the "RUDN University Program 5-100".

\section{References}

Akhmanova, O. S. (1966). Dictionary of linguistic terms. M.: Soviet encyclopedia.

Alexandrovskaya, L. V. (1973). Semantics of the term as a member of general literary vocabulary (based on the 
English marine terminology). Moscow.

Anisimova, A. G., Malakhova, V. L., \& Abdulrahimov, E. (2019). Challenges of translating polysemantic and multiequivalent terms within the framework of economic professional discourse. Professional Discourse \& Communication, 1(1), 46-54. https://doi.org/10.24833/2687-0126-2019-1-1-46-54

Anisimova, A., Pavlyuk, M., \& Kogotkova, S. (2018). Selecting a translation equivalent: Factors to consider in the classroom. Training, Language and Culture, 2(1), 38-50. https://doi.org/10.29366/2018tlc.2.1.3

Barkhudarov, L. S. (1975). Language and translation (questions of General and special theory of translation). Moscow.

Crystal, D. (2010). A Little Book of Language. Yale University Press.

Golovin, B. N. (1981). Types of terminological systems and the basis for their distinction. Term and word, Interuniversity, Gorky, 3-10.

Golovin, B. N., \& Kobrin, R. Y. (1987). Linguistic foundations of the doctrine of terms. Moscow.

Grinev, S. V. (1993). Introduction to terminology (p. 309). Moscow: Moscow State University.

IAEA-TECDOC-1516. (2006). Viability of inert matrix fuel in reducing plutonium amounts in reactors.

IAEA-TECDOC-1529. (2006). Management of reprocessed uranium.

IAEA-TECDOC-1707. (2013). Regulatory oversight of safety culture in nuclear installations.

IAEA-TECDOC-1804. (n.d.). Attributes of full scope level 1 Probabilistic Safety Assessment (PSA) for applications in nuclear power plants.

IAEA-TECDOC-1806. (n.d.). Nuclear power plant outage optimization strategy.

ISO technical committees ISO/TC 37. Language and Terminology".

ISO. (2009). ISO 704. Terminology work. Principles and methods. Geneva: ISO. Retrieved from https://www.iso.org/standard/38109.html

Ivanov, V. V. (1973). Terminology and borrowing in the modern Chinese Language. Moscow: Nauka.

Kaarpova, O., \& Kartashkova, F. (2007). Essays on Lexicon, Lexicography Terminography in Russia. American and other Cultures. Cambridge Scholars Publishing.

Kochergin, I. V. (2017). The basics of scientific and technical translation from Chinese into Russian. Moscow.

Leichik, V. M. (1971). On the relativity of the existence of the term. Scientific symposium. In Semiotic problems of languages of science, terminology and informatics (In 2 parts. Materials of the symposium - abstracts and annotations, pp. 436-442). Moscow.

Leichik, V. M. (2006). Terminology. Subject, methods, structure. Moscow.

Liu, Q. (2004) Approach for Definitions of Scientific and Technical Terms. China Terminology. Retrieved from http://www.term.org.cn/CN/abstract/abstract11256.shtml

Lotte, D. S. (1961) Fundamentals of building scientific and technical terminology. Questions of Theory and Methodology. Publishing house of the Academy of Sciences of the USSR.

Malyuga, E. N., \& Orlova, S. N. (2016). Teaching Professional English Terminology to Students of Economic Universities (pp. 7236-7241). EDULEARN16. Proceedings. Spain, IATED, 2016. https://doi.org/10.21125/edulearn.2016.0575

Malyuga, E., \& Tomalin, B. (2015). English Professional Jargon in Economic Discourse. Journal of Language and Literature, 5(4), 172-180.

Milroy, J (2001). Language ideologies and the consequences of standardization. Journal of Sociolinguistics, 5(4), 530-555. https://doi.org/10.1111/1467-9481.00163

Moiseev, A. I. (1971). Towards the definition of the term. In Semiotic problems of languages of science, terminology and informatics (pp. 336-338). M.: Moscow State University.

Ochirov, O. R., \& Lin, J. (2015). Issues of the Chinese terminology: from tradition "improving names" to modern theory. Vestnik of Lobachevsky University of Nizhni Novgorod, 3, 192-199. Retrieved from https://www.elibrary.ru/item.asp?id=24130301

Qiu, B. (2018). The current Terminological Infrastructures in China. China National Committee for Terms in 
Sciences and technologies. Beijing. from https://webcache.googleusercontent.com/search?q=cache:GcqdL1LtvKAJ:https://termcoord.eu/wp-ontent/u ploads/2018/07/Terminological-infrastructures-in-China.pdf $+\& \mathrm{~cd}=1 \& \mathrm{hl}=\mathrm{ru} \& \mathrm{ct}=\mathrm{clnk} \& \mathrm{gl}=\mathrm{ru}$

Sun, Q., Zhou, J.,Yan, Y., Zhang, P., Guo, H., \& Song, K. (2015). Analysis of temporal and spatial characteristics of carbon dioxide emissions from China's energy consumption industries (中国能源消费的 二氧 化 碳 排 放 时 空 特 征分 析). Retrieved from http://d.wanfangdata.com.cn/periodical/qdhgxyxb-skb201503007

Superanskaya, V. A., Podolskaya, N. V., \& Vasilieva, N. V. (2009). General terminology: theory. In Obshhaja terminologija: voprosy teorii. Moscow: Librokom.

Toury, G. (1980). In Search of a Theory of Translation. Tel Aviv: Porter Institute.

Vinokur, G. O. (1939). On some phenomena of word formation in Russian technical terminology (pp. 3-54). Trudy Mosk. Institute of history, philosophy and literature. Collection of articles on linguistics. Moscow.

Walmsley, J. B. (2006). Linguistic Terminology. In Encyclopedia of Language \& Linguistics (2nd ed., pp. 215-218). https://doi.org/10.1016/B0-08-044854-2/04760-X

Wang, Y., Ma, J., \& Fang, Y. (2016). Generation III pressurized water reactors and China's nuclear power. Zhejiang Univ.-Sci. A., 17, 911-922. https://doi.org/10.1631/jzus.A1600035

Wu, Y. (2017). Public acceptance of constructing coastal/inland nuclear power plants in post-Fukushima China. Energy Policy, 101, 484-491. https://doi.org/10.1016/j.enpol.2016.11.008

Xu, Y., Yuan, J., \& Wang, J. (2017). Learning of Power Technologies in China: Staged Dynamic Two-Factor Modeling and Empirical Evidence. Sustainability, 9, 861. https://doi.org/10.3390/su9050861

Ye, Q.-S. (2010). Difficulties of Term Translation (on Chinese.) Mezhdunarodnoe sotrudnichestvo v terminologicheskikh issledovaniyakh. Chita, 206-210.

Yuan, J., Li, P., Wang, Y., Liu, Q., Shen, X., Zhang, K., \& Dong, L. (2016). Coal power overcapacity and investment bubble in China during 2015-2020. Energy Policy, 97, 136-144. https://doi.org/10.1016/j.enpol.2016.07.009

Yuan, J., Xu, Y., Hu, Z., Zhao, C., Xiong, M., \& Guo, J. (2014). Peak energy consumption and $\mathrm{CO}_{2}$ emissions in China. Energy Policy, 68, 508-523. https://doi.org/10.1016/j.enpol.2014.01.019

Zhang, S., Li, Q. (2015). Development and scale analysis of China's nuclear power under low carbon suppression conditions. (低碳约束下中国核电发展及其规模分析) https://doi.org/10.3969/j.issn.1002-2104.2015.06.008

Zhao, C., Zhang, W., Wang, Y., Liu, Q., Guo, J., Xiong, M., \& Yuan, J. (2017). The economics of coal power generation in China. Energy Policy, 105, 1-9. https://doi.org/10.1016/j.enpol.2017.02.020

Zhao, Z. (2004). English-Chinese Chinese-English Linguistics Vocabulary Handbook.

Zhao, Z. (2010) Economic Research on Sustainable Utilization of Coal Resources in China (中国煤炭资源可持 续利用的经济学研究). Retrieved from https://xueshu.baidu.com/usercenter/paper/show?paperid=7d30caa6a890453cccfe9bb156a36acf\&site=xues hu_se

Zheng, S. P., \& Liang, Ailin. (2010). A General Survey of the State-of-the-Art of Terminology Studies Abroad. Mezhdunarodnoe sotrudnichestvo v terminologicheskikh issledovaniyakh. Chita, 10-13.

\section{Copyrights}

Copyright for this article is retained by the author, with first publication rights granted to the journal.

This is an open-access article distributed under the terms and conditions of the Creative Commons Attribution license (http://creativecommons.org/licenses/by/4.0/). 